\title{
ENSAIO SOBRE AS RELAÇÕES SOCIAIS DE PRODUÇÃO NAS ESTÂNCIAS DO RIO GRANDE DO SUL ${ }^{1}$
}

\author{
Francis Casagranda Zanella ${ }^{2}$ \\ Janaína Betto ${ }^{3}$ \\ Marcos Botton Piccin ${ }^{4}$ \\ Felipe Ferrari da Costa ${ }^{5}$
}

\begin{abstract}
RESUMO
Neste artigo, analisamos as relações sociais de produção constituídas nas estâncias do Rio Grande do Sul, com enfoque para as condições materiais e simbólicas que se estabeleceram nas interações das diferentes categorias de trabalhadores com os proprietários de terra denominados estancieiros. A literatura sobre o tema tem se debruçado sobre as dinâmicas relativas às estâncias no século XIX, prioritariamente. Aqui, analisamos transformações a partir dos anos 1940-1980, de forte ascensão social dos estancieiros e de oficialização de um estatuto do trabalho rural (1963), considerando suas repercussões sobre as relações de produção atuais. Os dados foram produzidos a partir de entrevistas com vinte e três trabalhadores/as, ou seja, com os estratos de baixo do espaço social. Nossos resultados iniciais apontam para insuficiências nas categorias trabalho assalariado e pecuária familiar na análise das condições em que a reprodução social de grupos familiares de trabalhadores/as se vinculam às grandes propriedades rurais.
\end{abstract}

Palavras-chave: Trabalhadores Rurais, Dominação, Campesinato Brasileiro.

\section{ESSAY ON THE SOCIAL RELATIONS OF PRODUCTION IN THE RANCHES OF RIO GRANDE DO SUL}

\begin{abstract}
In this paper we analyze the social relations of production constituted in the large cattle ranches of Rio Grande do Sul, focusing on the material and symbolic conditions that were established in the interactions of the different categories of workers with the ranchers. The literature on this subject has focused on the dynamics related to the ranches in the nineteenth century, primarily. Here, we analyze transformations from the $1940 \mathrm{~s}$ and $1980 \mathrm{~s}$, with the strong social rise of ranchers and the officialization of a rural labor act (1963), considering its repercussions on current relations of production. We produced the data from interviews with twenty-three workers, that is, from the lower strata of the social space. Our initial results point to shortcomings in the categories "wage labor" and "family ranching" in the analysis of the conditions under which social reproduction of workers' family groups is linked to large estates.
\end{abstract}

Keywords: Rural Workers, Domination, Brazilian Peasantry.

\footnotetext{
${ }^{1}$ Este artigo é uma versão revista e ampliada do trabalho apresentado no VIII Encontro da Rede de Estudos Rurais em agosto de 2018 na Universidade Federal de Santa Catarina, em Florianópolis (SC), no Grupo de Trabalho "Trabalho rural, mobilidade espacial e expropriação de direitos". O trabalho teve o apoio da Fundação de Amparo à Pesquisa do Estado do Rio Grande do Sul (FAPERGS); e da Coordenação de Aperfeiçoamento de Pessoal de Nível Superior (CAPES).

2 Doutorando em Ciências Sociais em Desenvolvimento, Agricultura e Sociedade no CPDA/UFRRJ. E-mail: franciszanella@gmail.com

3 Doutoranda em Extensão Rural no PPGExR/UFSM. E-mail: janaina.btt@hotmail.com

4 Doutor em Ciências Sociais. Professor nos programas de pós-graduação em Extensão Rural e em Ciências Sociais da UFSM. E-mail: marcospiccin@gmail.com

5 Doutorando em Ciências Sociais no PPGCS/Unicamp. E-mail: $\underline{\mathrm{f}} \operatorname{costa08@\text {hotmail.com}}$
} 


\section{INTRODUÇÃO}

Neste artigo, pretendemos discutir as relações sociais de produção constituídas nas estâncias do sul brasileiro, em especial na região chamada Campanha ou Fronteira Oeste do Rio Grande do Sul, especificamente no município de São Gabriel. Materializamos, neste trabalho, um primeiro conjunto de discussões que são conduzidas no âmbito do grupo de pesquisas 'Economia e sociedade estancieira: trajetórias conexas e práticas de reprodução social'.

As propriedades denominadas 'estâncias', baseadas na criação extensiva de gado, marcaram a ocupação das regiões de campos no Rio Grande do Sul a partir do século XVIII, sendo que dali emergiu um espaço social onde a figura dos senhores de terra, os 'estancieiros', concentrou terras, prestígio e poder. Considerando que a literatura sobre o tema tem se debruçado sobre as estâncias do século XIX, prioritariamente (Zarth, 2002; Cardoso, 2003; Farinatti, 2010; Maestri, 2010; entre outros), voltamos nosso olhar para processos que entraram em cena no século XX.

O recorte temporal aqui utilizado ainda carece de precisão, pois considera processos que têm ocorrido pelo menos desde o final do século XIX - devido aos efeitos da Lei de Terras de 1850 e do posterior cercamento dos campos (Zarth, 2002) - e vêm se reconfigurando até os dias atuais. Nesse sentido, para pensar as repercussões das dinâmicas sociais de longo prazo (Elias, 1980) sobre as relações de produção no presente, consideramos que o período entre 1940 e 1980 foi de forte ascensão social dos estancieiros, em grande medida devido à intervenção pública do Instituto Riograndense de Carnes em favor do setor (Piccin, 2014). É justamente nesse intervalo que se oficializa uma mediação jurídica das relações de trabalho rural no país, o Estatuto do Trabalhador Rural de 1963. Mais recentemente, nos anos 1990, a hegemonia dos estancieiros na região estudada sofreu abalos por duas ordens de fatores: a) a liberalização de mercados limitou seu controle sobre os preços das carnes; b) as condições de existência e exercício da dominação personalizada foram significativamente afetadas (Piccin, 2012).

Um ponto de partida que destacamos desde já, inspirado em Max Weber (1981), é a inexistência de um padrão fixo em termos de como se configuram as relações sociais nas diferentes estâncias e nos diferentes contextos locais, dentro de um mesmo município. Uma vez que as relações entre estancieiro e demais categorias subordinadas eram estabelecidas a partir de processos de dominação personalizados, portanto, da relação direta entre as partes, a constituição final de uma relação de trabalho dependia também do capital simbólico incorporado pelos agentes, o que poderia determinar particularidades em cada caso. No entanto, certos elementos têm sido recorrentes nos diversos contextos de relações sociais analisados e, por isso, orientaram a presente discussão.

As análises empreendidas neste artigo têm como base as seguintes questões gerais sobre relações sociais de produção: os trabalhadores/as de estâncias podem ser classificados como 
assalariados? Esses trabalhadores/as possuem apenas a sua força de trabalho ou também possuem algum meio de produção? Eles concebem alguma separação entre a jornada de trabalho necessária (para sua subsistência) e a excedente (apropriada pelo estancieiro)? Configura-se algum tipo de dívida moral/pessoal entre estancieiro e trabalhadores/as de estâncias? Os mecanismos legais do Estatuto do Trabalhador Rural são reconhecidos pelos trabalhadores/as desse espaço e influenciam os processos de exploração do trabalho ali estabelecidos? Existem mecanismos não capitalistas de acumulação capitalista que se expressam no trabalho nas estâncias?

O trabalho de campo que proporcionou este artigo foi realizado coletivamente em julho de 2017, a partir de interlocuções com agentes que ocupam posições subordinadas no espaço social, um polo basicamente composto por trabalhadores/as rurais e/ou pequenos/as proprietários/as de terra. Entrevistamos dezenove homens e quatro mulheres. Na maioria das vezes, conversamos com homens, mesmo que fossem casados com mulheres e que elas estivessem presentes no local da entrevista. Apenas duas dessas conversas foram realizadas com mulheres e outras duas com casais, isto é, homens e mulheres entrevistados conjuntamente. Essas relações que estabelecemos no campo possuíram um caráter de aproximações em relação ao objeto e ao espaço de estudo, o que denota o caráter exploratório deste trabalho e a predominância masculina entre os interlocutores.

A escrita deste texto priorizou o uso de categorias nativas na objetivação das relações sociais, ou seja, palavras que são usadas pelos entrevistados para expressar seu cotidiano, posições, sentidos e ações - as quais são destacadas entre aspas simples na primeira vez em que aparecem no texto. Além disso, refletiu-se sobre suas condições materiais a fim de compreender as posições no espaço social. Procurou-se trazer elementos empíricos de análise, com o intuito de auxiliar na compreensão de padrões recorrentes de relações sociais, conduzindo diálogos com a literatura especializada nas relações de produção em torno de grandes propriedades fundiárias (Weber, 1981; Garcia Jr., 1989; Sigaud, 1996; 1979; Palmeira, 2009; Martins, 2010). Com um olhar sobre trajetórias sociais específicas em diferentes posições no espaço social, percebemos como as categorias nativas se revelam complementares, relativas e não estanques quando colocadas em diálogo junto a conceitos recorrentes na literatura sobre a região da Campanha, entre os quais trabalho assalariado e pecuária familiar.

\section{DINÂMICAS DA FORÇA DE TRABALHO: 'MENSAIS’ E 'DIARISTAS'}

A fim de esboçar algumas respostas às questões aqui colocadas, tomaremos nas próximas páginas duas categorias nativas que se mostraram importantes para definir ocupações atualmente destinadas ao trabalho, sendo elas: 'mensal' e 'diarista'. Essas categorias de trabalho são as responsáveis pela 'lida' nas estâncias. À primeira vista, a lida significa qualquer trabalho realizado 
por alguma pessoa (independente do seu gênero), no âmbito da estância ou fora dela, mas, quando olhada atentamente, indica uma atividade heterogênea e dotada de vários sentidos.

As categorias mensal e diarista auxiliam na análise das dinâmicas de recrutamento da força de trabalho que faz a lida nas estâncias. O trabalho mensal nas estâncias é na maior parte realizado pela categoria dos 'peões'. Mensal não significa que o trabalhador seja contratado mensalmente, mas indica a temporalidade do salário. Identificamos as seguintes funções masculinas na lida das estâncias: a) o ‘campeiro' é aquele que trabalha no manejo de bovinos, ovinos e equinos; b) o 'caseiro' é aquele que fica responsável por administrar o 'galpão' onde ficam alojados os campeiros, o que muitas vezes envolve preparar refeições e fazer a limpeza do local; c) pode caber ao 'caseiro' ou a um peão específico fazer 'serviços gerais', como manutenção de instalações da sede da estância; d) o 'posteiro' é aquele que reside em uma porção afastada ou isolada da sede da estância, o chamado 'posto', sendo que faz a lida com os animais tanto no posto como junto com os campeiros, conforme a demanda; e) o 'capataz', uma espécie de gerente das atividades campeiras.

Cabe destacar que alguns peões podem exercer outras atividades em determinados momentos, como as de inseminação artificial, reparo de cercas, preparo de instrumentos de couro para o trabalho. Ou seja, a condição do peão mensal não especifica a priori o conjunto de tarefas que este agente social desempenhará. Seu ramo de trabalho é, ao mesmo tempo, homogêneo na noção de peão e altamente diversificado nas tarefas cotidianas. Em outras palavras, o peão, no âmbito do espaço estancieiro, é alguém que 'faz de tudo', algo declarado com grande frequência entre esses trabalhadores.

Mas a indiferenciação enunciada pelo ‘fazer de tudo' não indica que todos os peões o farão efetivamente. Há uma diferença significativa entre: a) saber atuar nas diferentes funções supracitadas e b) estar obrigado a desempenhar todas as atividades daquele rol. Tal distinção se aproxima daquela percebida por Moacir Palmeira (2009) em relação aos moradores de engenho da Zona da Mata de Pernambuco, uma configuração social similar à estância nos termos da dominação personalizada e da concentração fundiária. Enquanto a experiência de trabalho acumulada pelo morador - 'saber fazer todo serviço' - era sinal de qualificação social entre os trabalhadores e elemento valorizado pelos senhores de engenho, estar obrigado a 'fazer todo serviço' era o oposto em termos de legitimação e de subordinação.

Os capatazes são uma categoria hierarquicamente distinta entre os trabalhadores mensais, ocupando função de gerência e também de lida junto aos demais trabalhadores das estâncias. Os capatazes respondem pelos estancieiros em sua ausência. Estes costumam fazer apenas visitas esporádicas na fazenda, de modo que os capatazes incorporam no exercício de suas funções a posição de mando direto da força de trabalho e de administração geral: fazem a contratação de peões, a aquisição de insumos e o trabalho de manejo de animais junto com os demais peões. Mais que 
empregados do estancieiro, os capatazes costumam dizer que 'cuidam' ou 'reparam' a estância. Isso supõe uma relação não apenas formal/legal, como veremos mais adiante.

Note-se que as configurações de trabalhadores mensais em cada estância podem ser bastante variáveis. Nos casos que tivemos contato no trabalho de campo, em estâncias possuindo entre 800 ha a 2000 ha, havia, em geral: um capataz, de um a três peões campeiros, um ou nenhum caseiro e um posteiro apenas no caso de ter porção isolada da estância a ser cuidada. Além deles, poderia haver também uma 'cozinheira', mas sua situação não fica rigidamente categorizada entre mensal e diarista, como veremos adiante.

Outra importante categoria de trabalhadores das estâncias são os diaristas, ou seja, trabalhadores remunerados 'por dia' de trabalho executado. Esses trabalhadores geralmente são 'chamados' quando o trabalho 'aperta' na estância, ou seja, nos picos de trabalho, como em casos eventuais onde o gado é reunido na 'mangueira' e onde se fazem atividades de vacinação, inseminação, etc. A mangueira é uma espécie de cerca arredondada, construída com madeira, que facilita as lidas com o gado ao restringir sua mobilidade. Além disso, diaristas podem ser contratados para fazer atividades de tosquia das ovelhas, os quais são chamados de 'esquiladores'. Outra modalidade em que pode acontecer a contratação de diaristas é na edificação de benfeitorias nas estâncias, como na construção de mangueiras e no feitio de cercas assumido pelos 'alambradores'.

Tanto para os esquiladores quanto para os alambradores é relativamente comum que as atividades sejam remuneradas somente em dinheiro e sob a modalidade de 'empreitada', onde os trabalhadores não são remunerados por dia, mas por atividade realizada, por exemplo: quilogramas de lã 'tosquiada', metros construídos de cerca ou de mangueira. Os contratados por regime de empreitada podem levar consigo outros trabalhadores para executar a atividade, sob sua responsabilidade, que poderão estabelecer entre si alguma forma de divisão do valor recebido pela empreitada.

Quando existem mulheres que se ocupam em estâncias, sua função geralmente é denominada como 'cozinheira'. Além de cozinhar para os demais trabalhadores e para os familiares dos estancieiros em suas visitas eventuais, elas geralmente são também responsáveis por serviços domésticos como limpeza dos quartos e das roupas dos peões, bem como da casa e das roupas dos familiares dos estancieiros.

Nas estâncias, quando há o cultivo de culturas como a de mandioca para alimentação dos trabalhadores e dos integrantes da família do estancieiro, este pode ser realizado tanto pelo peão caseiro como pela cozinheira. Neste mesmo contexto encontramos a criação de pequenos animais como galinhas e ovelhas. A criação das galinhas é realizada próxima à sede da estância, sob responsabilidade do peão caseiro ou da cozinheira, assim como o abate das mesmas. Faz parte da lida dos peões a criação das ovelhas para a alimentação interna da estância, realizada na mesma área de 
pastejo dos bovinos. O abate tanto de ovinos como de bovinos também é realizado por peões, seja para a alimentação interna na estância ou da família do estancieiro na cidade.

Uma condição que pareceu comum entre as cozinheiras é de serem esposas de peões caseiros ou de capatazes da estância, residindo nela. No entanto, também identificamos cozinheiras que eram moradoras das proximidades das estâncias, sem vínculos matrimoniais com seus trabalhadores. Assim, as mulheres ocupadas em estâncias como cozinheiras figuram tanto na condição de mensais como diaristas.

Ressaltamos que há uma lacuna significativa de investigação no sentido de objetivar as relações sociais de produção implicadas no trabalho feminino nas estâncias. Quando considerados os estudos que versam sobre gênero no mundo rural em outras partes do sul do país, emerge como objeto recorrente a agricultura familiar em territórios onde predominam as colônias de imigrantes europeus e seus descendentes, como é o caso das regiões coloniais de parte do estado de Santa Catarina e das regiões Norte e Serra do Rio Grande do Sul (Seyferth, 1985; Paulilo, 1987; 2004; Woortmann, 1990; Carneiro, 2001; Brumer, 2002; 2004). No caso do espaço sob influência das estâncias no sul do país, atentamos para mulheres rurais que se encontram em setores sociais distintos da condição das colônias parcelares, onde ganha centralidade a presença das grandes propriedades de terra frente às práticas de reprodução social. A incipiência de estudos aqui referida está ligada a essa condição social, o que não impede que se construam diálogos com tal literatura e, sobretudo, com aquela que aborda a temática em outras regiões brasileiras atravessadas pelos grandes domínios rurais (Paulilo, 1987; Woortmann, 1990; Cerqueira, 2017).

Em relação aos pagamentos feitos ao conjunto de trabalhadores mensais, existem diversas formas de estabelecer um 'trato', ou seja, um acordo de teor legal e também pessoal entre trabalhador/a e estancieiro, que envolve dinheiro, alimentação, moradia, instrumentos de trabalho e capital simbólico. A cessão de áreas para fazer hortas ou 'cercados' para o peão ou capataz se demonstrou como prática muito rara, tendo sido gradualmente extinta desde a década de 1970. Da mesma forma, a prática de ceder ao capataz o acesso aos campos da estância para que ele crie algumas cabeças de gado próprias também está cada vez mais restrita, embora ainda exista. Um ex-capataz por nós entrevistado relatou que ao deixar a estância onde trabalhava para então se aposentar levou consigo uma pequena tropa de 50 cabeças de gado, resultado de um pequeno número inicial de animais que ao longo dos anos se reproduziu. Voltaremos a esse assunto. Mas é importante assinalar que é somente ao capataz que era dado esse privilégio, um prêmio similar ao sítio, que era concedido pelos senhores de terras aos moradores de engenhos pernambucanos que mais internalizassem as regras do ciclo de retribuições da morada (Palmeira, 2009).

O instrumento formal da assinatura de Carteira de Trabalho é um elemento presente desde a década de 1970, apesar de que isso não tem implicado que os direitos oficializados pelo Estatuto do 
Trabalhador Rural sejam efetivados pelo empregador e/ou conhecidos/demandados pelo empregado. Essas condições só surgem a partir da década de 1990, quando se intensificam as reclamações judiciais trabalhistas em meio ao enfraquecimento das condições de existência e exercício da dominação pessoal pelos estancieiros (Piccin, 2012).

Um paralelo pode ser feito com o estudo de Lygia Sigaud (1996), sobre a intensificação das mobilizações judiciais trabalhistas contra os senhores de engenhos da Zona da Mata pernambucana nos anos 1990. A autora sugere, pensando como Max Weber, que o direito é apenas um aspecto das relações sociais, não uma fonte única de sentidos para as ações. Ou seja, mesmo que existam os direitos e até a carteira de trabalho, deve-se analisar as condições de possibilidade para o efetivo regramento das relações trabalhistas. Deste modo, feita uma descrição inicial das relações sociais de produção nas estâncias, faremos algumas considerações de maior amplitude temporal e teórica nas próximas páginas.

\section{ESTANCIEIROS E TRABALHADORES: ENTRE CONCESSÕES E DIREITOS}

As relações sociais de produção no trabalho das estâncias conservam traços não capitalistas enquanto mecanismos da reprodução capitalista do capital dos proprietários estancieiros, em termos similares ao observado por José de Souza Martins (2010) acerca das relações de colonato nas fazendas cafeicultoras paulistas, entre finais do século XIX e meados do século XX. É dizer: a existência de dinheiro nas relações não implica que a forma de salário tipicamente capitalista esteja desenvolvida. A fragilidade com a qual os princípios legais são internalizados na intermediação entre estancieiros e seus trabalhadores/as decorre num sentimento de ambiguidade para estes: entre os direitos nem sempre efetivados no presente e as concessões dos senhores em um passado idealizado. Para adentrarmos esta seara, vejamos algumas falas de um dos peões de estância entrevistado, o Alberto ${ }^{6}$, de 64 anos, descendente de pequenos proprietários (uma área de 2 hectares), casado, três filhos e possuidor de um 'pátio' (residência) na cidade de São Gabriel:

É, tinha estância velha que tocava, de primeiro a estância não era como agora. Agora tem estância que tu trabalha umas oito horas. Mesmo que tenha outros serviços, tu não é obrigado a trabalhar mais que oito horas nas estâncias. A gente trabalha, eu trabalho, não dou bola pra isso aí. Mas tem estância que, se tu trabalhar mais de oito horas, eles fazem hora extra já, e tem estância que não te deixa trabalhar mais que oito horas.

$* * *$

Se tu trabalhar com arreiamento da estância, a estância não te paga por instrumental de arreio. Mas a bota é obrigatório. E tem estâncias que ainda não dão [pares de botas], é obrigatório, mas eles se fazem de... têm muitas aí. E o pessoal de estância não é muito exigente né. Por isso que esses guris que trabalhavam aí foram trabalhar no frigorífico. Agora há pouco eu encontrei um, ele me dizia: "não, não adianta, tu vê, na estância posso até ganhar a mesma coisa, ou mais, mas aí tu gasta bota, tu gasta cinto, tu gasta tirador, tu gasta isso e gasta

\footnotetext{
${ }^{6}$ São fictícios todos os nomes aqui utilizados para se referir aos interlocutores no trabalho de campo.
} 
aquilo", e tem umas que não dão. E tu entra lá no frigorífico e te dão tudo. Tu entra lá, te dão sapato, te dão a roupa, tu não gasta nada ali, chega o fim do mês e te dão a cesta básica. [...] Então o cara ganha, se fizer as contas tu ganha mais, e é verdade. E todos os dias eu estou em casa junto com a família [caso trabalhar no frigorífico. Pois se trabalhar nas estâncias retornará para casa, via de regra, em apenas um final de semana a cada 15 dias].

***

Um tratorista aí numa granja, hoje, ele está ganhando melhor que o cara [peão]. E quase todos eles têm uma porcentagem. Tu trabalha aí por um salário que existe na estância que é mais ou menos de 1200 e pouco, aí tu entra em uma granja dessas ganhando isso aí. Mas aí tu ganha, vamos dizer que, de 50 sacos de soja, no fim da colheita, aí tu pega tudo junto, aí tu vai ainda ganhar alguma coisinha. [...] eu sei que no fim das contas tu vai ganhar mais lá [na 'granja'].

Seguindo as pistas dessa e de outras falas recorrentes em campo e bem representadas por Alberto, os trabalhadores de estâncias situam pelo menos outras duas categorias sociais para além da deles, peões: a) os trabalhadores de frigoríficos que beneficiam a carne de bovinos abatidos industrialmente; e b) os tratoristas de estabelecimentos que cultivam cereais, as 'granjas'. Trabalhar em estância como peão seria, para eles, a pior ocupação relativa porque, não raro, não há a indenização por parte do estancieiro dos materiais gastos no trabalho, como o 'arreiamento' dos cavalos, as botas, o cinto e o tirador, citados como os principais. Portanto, em muitos casos, são os próprios trabalhadores, ao invés dos empregadores, os responsáveis por restabelecer as condições de trabalho a cada ciclo em que esses instrumentos se desgastam. Os ingressos mensais monetários do peão não são usados exclusivamente na obtenção dos seus meios de subsistência, pois se diluem parcialmente na reposição de instrumentos de trabalho.

Outras duas situações nas quais os peões localizam as condições de seu trabalho na estância enquanto inferiores às dos demais empregos percebidos são a cesta básica, recebida ao final de cada mês no frigorífico, e a participação nos resultados da produção das granjas, que, mesmo pequena, "tu pega tudo junto". Assim, mesmo que o salário nominal seja semelhante ao do trabalhador de frigorífico ou do trabalhador de granja, ele sabe que, "no fim das contas", nessas ocupações "tu vai ganhar mais". Além disso, diferentemente do frigorífico, o trabalho como peão só permite que ele se desloque para ficar com a sua família em um final de semana a cada 15 dias, uma vez que a casa está situada na cidade de São Gabriel.

Mas, tão importante quanto a classificação que eles próprios fazem das ocupações que podem estar em seus arcos de possibilidades, é notar o modo como mecanismos legais se inserem no intermédio das relações sociais de produção. A extensão da jornada de trabalho sem o pagamento de hora extra pode ser legitimada em termos da honra do peão que "não dá bola pra isso aí", no sentido de que pode estender uma jornada de trabalho sem cobrar dinheiro por ela, mesmo sabendo do direito a receber maior remuneração. Assim, quando Alberto nos diz que "não é obrigado a trabalhar mais que oito horas", nos remete a pensar na noção de obrigação e no que implica em termos legais e 
pessoais. Note-se a singularidade dessas relações peão-estancieiro, pois possuem lógicas implícitas nas quais existe orgulho em trabalhar mais que oito horas, colocando em suspenso o regime legal.

Uma vez que está implícita na estrutura de relações simbólicas da estância uma acumulação de prestígio junto ao senhor de terras, pela qual um peão não se importe em trabalhar além da jornada legalmente instituída sem a remuneração devida, o não cumprimento do estatuto do trabalho rural é um risco que o estancieiro escolhe correr, dado que as condições mínimas para o peão acioná-lo judicialmente estão presentes. O que está em jogo é que, se o peão não se sentir retribuído do modo socialmente esperado pelo esforço demonstrado ao estender sua jornada de trabalho sem cobrar em dinheiro por ela, o caminho de reparação judicial pode se apresentar a ele como legítimo (Piccin, 2012). O sentimento de retribuição ao qual nos referimos não passa, necessariamente, pela moeda e salário, mas, especialmente, pelos prêmios (Palmeira, 2009) que podem ser esperados de um patrão: concessão do campo para colocar uma pequena quantidade de gado, confiança expressa na ascensão à posição de capataz, permissão de residir na estância com esposa e filhos, etc. Voltaremos às características do ciclo de retribuições das estâncias na próxima seção.

De qualquer forma, tudo isso acaba se relacionando com percepções de que a posição de peão passou por certa corrosão relativa perante outras ocupações no que se refere à manutenção de seus meios de vida, já que, "se fizer as contas", na estância o entrevistado percebe obter menor remuneração. A constante reclamação das classes dominantes dessa região quanto à falta de 'boa' mão de obra (Piccin, 2012) pode estar associada com essas condições objetivas de remuneração desfavoráveis à escolha ocupacional como peão.

Como já dito, existe certa ambiguidade por parte de alguns peões entre os atuais direitos trabalhistas reconhecidos para a categoria frente às concessões que os estancieiros lhes faziam em décadas passadas. Vejamos outro trecho do relato de Alberto, peão que está prestes a se aposentar, quando nos deu uma representação sobre o passado:

[...] tinha esses homens velhos, mais antigos aí - agora não tem dessa idade -, mas tinha gente com ponta de gado, cem reses, duzentas reses, invernada de gado. Mas também não tinham direito, quando saíam, era aquilo. Direito dele era aquilo que eles arrumavam ali. Mas hoje se deixassem os caras fazerem isso aí, era uma boa (riso). Mas aí foi mudando. Aí foi, tu vê, direitos que não tinha, hoje aparecem.

Consideramos que a fala desse entrevistado representa formas distintas de pensar as remunerações: antes e depois dos direitos. Para ele, enquanto peão, não é mais permitido ter uma 'ponta de gado' própria na estância porque "foi mudando" e os "direitos que não tinha, hoje apareceram". Eliminou-se uma possibilidade restringida de acumulação que foi recorrente no passado porque o "direito deles era aquilo que eles arrumavam ali", com a concessão de uma ponta de gado pelo estancieiro. Isso permitia constituir uma espécie de poupança utilizada em caso de urgências ou 
na condição de se desligar da estância com recursos para reformar ou mesmo construir uma moradia na cidade.

Assim, quando Alberto comenta que "era uma boa se deixassem fazer" uma ponta de gado, revela, por um lado, a idealização do passado, já que nem todos os peões obtinham a concessão de uma ponta de gado, e, por outro lado, a ambiguidade em relação ao modo particular de internalização do estatuto jurídico em sua relação com o estancieiro. Como vimos, o salário do peão nem sempre remunera de acordo com os direitos trabalhistas, já que ocorre de os instrumentos de trabalho serem financiados por ele mesmo, sem indenização. Ao mesmo tempo, a oficialização da relação trabalhista impede o que consideramos uma forma restringida de acumulação tutelada no contexto da grande propriedade, isto é, acarreta na extinção de práticas como a ponta de gado.

Situação similar foi apreendida na plantation canavieira do brejo paraibano, estudada por Afrânio Garcia Jr. (1989), numa transição onde as relações tradicionais de morada foram substituídas por outras formas de contratação dos trabalhadores. Para os ex-moradores, sair dos engenhos era como deixar um 'cativeiro'. Eles se consideravam 'libertos' porque não precisavam mais atender as expectativas dos senhores de engenho. Porém, os agentes que vivenciavam essa transição idealizavam o passado da morada, mas não no sentido do cativeiro, e sim pela percepção de contínuo aumento das privações em dimensões concretas de suas vidas (Sigaud, 1979). Ou seja, ao passo em que cresciam os pagamentos monetários nos engenhos, subiam também os custos com alimentação agora adquirida nas feiras e não mais obtida diretamente nos próprios sítios e roçados. Os ex-moradores relacionavamse com mercados tanto na venda de seu trabalho como no acesso à terra. A emancipação desses sujeitos sociais era, ao mesmo tempo, facilitada pela saída do cativeiro da morada e restringida pelas privações materiais do pauperismo (Garcia Jr., 1989).

Portanto, quando o peão de estância supracitado diz que "era uma boa" se a ponta de gado ainda fosse concedida pelos estancieiros, está conjecturando uma resposta para as privações na reprodução das condições de existência em um cenário de corrosão nas remunerações. Como saída, ele imagina a concessão da ponta de gado enquanto medida para reduzir privações. Esta é uma prática não capitalista que historicamente permeou as relações de dominação personalizada com estancieiros, porém, é também uma forma tutelada de reprodução de um campesinato pecuarista junto da estância. Tal situação de ambiguidade entre antigas concessões e novos direitos se mostrou recorrente em outros contextos de transição para o trabalho assalariado no rural brasileiro. Entendemos que esse processo social no caso estancieiro ainda merece maiores investimentos de pesquisa a fim construir dados e análises. 
Nesta seção, faremos algumas considerações sobre a condição do capataz nas relações sociais de produção da estância, refletindo sobre algumas representações que a permeiam e buscando relacioná-las com as representações em torno de outras posições do espaço social, notadamente a do peão de estância. Nesta reflexão será central a noção do 'compromisso'.

O capataz se encontra sob algumas condições de maior poder perante os peões, tanto no sentido da posição de mando, como nas melhores remunerações, e também na possibilidade dada a alguns deles para manejar uma ponta de gado próprio na estância. Por outro lado, vive também condições similares às do peão, seja pelas extensas jornadas de trabalho ou pela necessidade de usar instrumentos próprios de trabalho, arcando com seus custos. Porém, devido à possibilidade de manejar sua ponta de gado, o capataz sente-se em vantagem, como se estivesse dedicando certo montante de trabalho totalmente para si. Por sua vez, o estancieiro consegue um trabalhador com alta capacidade de gerência técnica e de pessoal por um custo similar ao do peão, sendo que se abstém de parcela do pagamento do salário na medida em que permite a ele ter criação própria de gado.

Sendo assim, a condição do capataz é ambígua, pois vê que o trabalho que é dedicado para seu patrão também o é para si mesmo, na medida em que o seu gado e o do patrão são manejados de forma conjunta. Em certa medida, o capataz paga em gado ao patrão o direito de criar seu próprio gado. A renda da terra é entregue gratuitamente ao estancieiro pelo direito de poder criar uma ponta de gado em terra alheia. Essa relação é muito próxima do que acontecia com os imigrantes na relação de colonato em São Paulo. Naquele contexto, Martins (2010) analisou que os colonos viam na produção de café colhida e entregue aos patrões um tributo para que pudessem ter seus próprios cultivos de subsistência e venda. Pode-se comparar que, tanto quanto o colono que plantava café para o patrão de modo consorciado com seus cultivos de subsistência, o capataz não vê nitidamente a separação entre trabalho necessário para obter seus meios de subsistência e trabalho excedente apropriado pelo estancieiro, pois seus gados estão distribuídos pelos mesmos campos. No caso do capataz, se revela com força o que Weber (1981) chamou de comunidade de interesses, ou seja, o capataz possui o mesmo interesse que o estancieiro tem em ver o gado ganhando peso.

$\mathrm{O}$ ato de permitir uma ponta de gado era uma estratégia dos estancieiros para aumentar o compromisso dos capatazes. Um compromisso que segue sendo exigido, mas agora cada vez mais sem a ponta de gado. Uma situação presenciada a campo por Piccin (2012) revela bem a tentativa dos estancieiros em não fazer um compromisso que tinha por base a ponta de gado. O autor estava realizando uma entrevista na casa de um estancieiro quando a campainha tocou e o mesmo foi atender. Depois de alguns minutos, o estancieiro retornou e logo comentou que quem havia tocado a campainha foi um candidato a capataz em sua estância, uma vez que o antigo capataz se aposentara. Mas, disse o estancieiro, agora seria diferente: não aceitava mais a ponta de gado como parte do trato com seu capataz, e que o candidato ficara de pensar a respeito. Em havendo a necessidade de cumprir 
o regramento legal da legislação trabalhista, a ponta de gado estava se tornando dispensável para os patrões nos compromissos firmados com os capatazes. Nesse sentido, a categoria compromisso aparece como relação necessária entre peão/capataz e estancieiro, como parte constitutiva do vínculo entre eles em contraposição ao vínculo intermitente do diarista, mesmo quando a referência é a legislação trabalhista.

O compromisso é uma relação pessoal do mensal com o estancieiro, para além das formalidades contratuais legais, estabelecido em termos de mútuo reconhecimento dos capitais simbólicos assimetricamente distribuídos entre estancieiro e capataz. Obviamente a relação entre ambos inclui certas obrigações legais. Mas, sem elas, diz respeito a uma relação pessoal com o patrão, uma honra a cumprir. Nesse sentido se expressa a categoria que designa o trabalho do capataz: ele não é mero empregado, ele cuida da estância. Essa é uma expressão forte da condição de compromisso, onde a contrapartida do estancieiro é a confiança no capataz, ou seja, o reconhecimento de seu compromisso. Se não fosse o compromisso, qualquer pessoa experiente na lida poderia ser capataz.

Portanto, para além de uma função de gerência, 'cuidar' exige se sentir responsável pela propriedade privada do patrão como se fosse algo seu, implica um completo reconhecimento da legitimidade do estancieiro como proprietário, por mais que ele seja absenteísta. Para exemplificar como o capataz tende a representar sua posição, podemos citar um trecho da entrevista com Henrique, que tem 68 anos, é descendente de pequenos proprietários (6 hectares), é casado com Raquel, são aposentados e residem na cidade, além de proprietários de 120 hectares onde a filha e o genro trabalham, este inclusive como capataz de uma estância vizinha. Henrique demonstrou orgulho de ter sido "capataz mesmo, não era daqueles que tem que esperar o patrão resolver. Eu não, quem resolvia era eu.”. Em certa medida, essa citação expressa como existe uma personificação do estancieiro na figura do capataz. Isto é, não se trata de mero repasse de responsabilidade, mas da possibilidade mesmo de o capataz poder falar e mandar em nome do estancieiro na esfera cotidiana do trabalho.

Também citamos outro caso, do entrevistado Ronaldo - filho de peão que 'fazia de tudo' e morava em bairro periférico da cidade -, de 38 anos, aposentado por invalidez, casado, tem dois filhos e três filhas. Junto da esposa e um filho, Ronaldo é beneficiador e vendedor de lenha rachada para fogão, tendo trabalhado em mais de uma oportunidade como capataz. Na conversa com ele, relatounos como rompeu, certa vez, seu trato com um estancieiro quando era o capataz de sua estância. Isso se deu quando o filho do estancieiro passou a dar ordens na estância, sem consentimento do capataz, o que foi visto como intromissão. Ou seja, o filho não respeitou as regras do jogo e expressou desconfiança no capataz, o que pôs fimm àquela relação. Não havia mais condições de sustentar o compromisso entre as partes. 
Ter compromisso também é condição necessária para a ascensão social de grupos subordinados no trabalho do campo, aos quais se impõe a posição social de peão, e que almejam alcançar a de capataz. É requisito para ocupar posições de maior prestígio. É o preço para ter melhores condições de remuneração e de poder residir junto de sua família, uma vez que, geralmente, o capataz ganha casa na estância para que sua esposa trabalhe na polivalente função de cozinheira. Além disso, de poder ter uma ponta de gado para vendê-la no futuro e de obter renda para adquirir uma 'chácara' ou uma casa na cidade. Enfim um conjunto de benesses relativas que resultam do reconhecimento do compromisso.

Portanto, é possível traçar algumas considerações gerais sobre as relações fortemente personalizadas entre capataz e estancieiro que se mostraram recorrentes: o peso do compromisso, o sentido de cuidar a estância, a relação à distância com os patrões, a possibilidade de ter ponta de gado - embora esta seja cada vez mais restrita.

\section{AUTONOMIA RELATIVA OU SUBORDINAÇÃO AMPLIADA? TRABALHO 'POR CONTA' E AS 'CHÁCARAS'}

É peculiar a forma como se configura a categoria de trabalhador rural no âmbito estudado. A partir de nossas entrevistas, percebemos que, com certa frequência, os trabalhadores de estâncias possuem pequenas propriedades, cuja categoria nativa as denomina como 'chácaras'. Junto disso, consideramos que os estabelecimentos agropecuários de até 10 hectares representam $22 \%$ do total no município de São Gabriel (IBGE, 2006). Tais dados nos levam a supor que existe uma dinâmica social para além do indivíduo assalariado na estância, que se alia a estratégias familiares de reprodução social com base em pequenas propriedades. Utilizaremos de noções teóricas como autonomia e subordinação na reprodução social do grupo familiar para discutir seus desdobramentos nas relações sociais de produção das estâncias.

No trabalho de campo fizemos a seguinte pergunta dicotômica em algumas entrevistas: “possui terras ou trabalha em outras propriedades?”. Em nossa conversa com Camilo, 50 anos, casado com Angélica, pequenos proprietários e, ele, peão de estância, ouvimos dele o seguinte: "Não, eu tenho um pedacinho de terra, que é a minha chácara, onde eu trabalho. E trabalho também pra fora [da chácara], porque pra sobreviver com uma chacrinha pequena a gente não sobrevive."

Essa chácara de 13 hectares, que foi adquirida durante a trajetória familiar, não foi herdada. O trabalho nela possui caráter familiar. Perguntamos também se o entrevistado passava mais tempo nas estâncias ou na chácara, tendo resultado na seguinte resposta: “Quando eu não estou [na chácara] - porque às vezes eu estou cuidando fazenda ou trabalho de peão - aí estou na fazenda. Mas se sair da fazenda, tipo, não deu certo mais com um patrão, aí volto pra lá [chácara].” 
Ao mesmo tempo, sua esposa Angélica está continuamente lidando na chácara com o "serviço do dia a dia e ajuda na volta", "criando coisas, fazendo horta, plantando". Nisso, "a gente tem que estar sempre girando", sem parar, a fim de "tirar dinheiro para viver".

A partir dessas falas, pode-se considerar que, se a família "não sobrevive" somente com a 'chacrinha', o mesmo seria válido para "sobreviver" somente trabalhando 'fora'. Entre chácara e estância se expressa uma ambivalente complementaridade. Ao mesmo tempo em que a pequena chácara viabiliza uma autonomia relativa em relação aos patrões, o que permite romper o contrato quando "não dá certo" com um deles, também possibilita ampliação da subordinação aos grandes proprietários na medida em que as remunerações aos empregados podem ser mais baixas, já que possuem acesso a um meio de produção própria da subsistência. Assim, a exemplo do que se verificou em Weber (1981) e Martins (2010), consideramos que a disponibilidade de trabalhadores que possuem acesso a pequenas parcelas de terra pode permitir ao senhor de terras rebaixar o padrão de remuneração monetária.

Nesse contexto, observa-se a complementaridade entre trabalhar na estância e trabalhar na chácara, onde a força de trabalho dos membros do grupo familiar é distribuída. A chácara é um espaço onde são manejados plantações e animais tanto para consumo da família como para venda de excedentes, particularmente em fazer as 'quitandas', ou seja, atividades geralmente atribuídas às mulheres e que envolvem vendas de alimentos artesanalmente processados, baseados em leite, ovos, frutas e legumes obtidos na chácara. A posse da chácara e de meios de produção nas mãos da família de trabalhadores acaba gerando o sentido de autonomia por eles vivenciado, de ser espaço onde "tiram dinheiro para viver". No entanto, como já foi mencionado, esse tempo de trabalho vivenciado como algo para si abre brechas para que os estancieiros restrinjam ainda mais os salários, já que oferecer parte dos meios de subsistência não estará sob sua responsabilidade, mas da chácara.

Encontramos outro caso similar de pequeno proprietário que não percebe dicotomia em relação a trabalhar 'pra fora', o que foi destacado pela categoria 'trabalhar por conta'. Esse entrevistado, que chamaremos Adolfo, tem pouco mais de 30 anos, é casado com Roberta e filho único. Relatou que "plantava bastante" junto de seus pais na propriedade de aproximadamente 100 hectares da família, mas hoje não cultiva milho porque "não vale mais a pena", considera que "mais vale trabalhar pra fora do que plantar". Contudo, não está falando em ser um mensal, mas de trabalhar por dia em serviços especializados de manejo de gado junto do principal proprietário da localidade, situação na qual considera que "o cara é mais livre. Ser empregado num mês é brabo. Aí o cara não se governa.". Assim, associa o trabalho por dia com vantagem, com "liberdade".

Portanto podemos levar em conta que a condição na qual Adolfo opta por uma ocupação enquanto diarista é muito distinta daquela dos que dependem exclusivamente do trabalho por dia ou por mês. De um modo relacional, percebe-se que o trabalho mensal ou diarista é assumido como 
tarefa central nos casos de famílias ou de trabalhadores solteiros que possuem maiores restrições para obter outras fontes de renda. E essa condição não se restringe somente ao tamanho da propriedade. Destacamos aqui o caso de Cleber, 38 anos, casado com Giovana, ambos morando junto de sua filha e do pai de Cleber em uma chácara de menos de 3 hectares. Cleber já trabalhou 'pra fora' como mensal, mas atualmente nem mesmo 'por dia' ele trabalha, somente 'por conta', nos diz. Ou seja, considera que tem maior controle sobre o modo e o tempo de uso de sua mão de obra. Isso se deu conforme passou a trabalhar com produção artesanal de cordas em couro, sendo que abastece estâncias e estabelecimentos comerciais da cidade com seus produtos, sem depender das aquisições de um estabelecimento em específico.

Aqui sentimos a necessidade de fazer uma ressalva sobre a condição de trabalhadores diaristas. A condição de escolha por trabalhar como diarista no caso de Adolfo supõe a existência de condições materiais consolidadas. Ao mesmo tempo, existe outro conjunto distinto de trabalhadores por dia: possuem acesso restringido à terra, não possuem produção artesanal que lhes garanta autonomia, não têm a mesma relação de compromisso/subordinação com os estancieiros como no caso dos mensais. Nessa condição existem diferentes trabalhadores: desde aqueles em situação mais pauperizada no espaço social - às vezes também chamados de 'moradores de corredor', famílias que se estabelecem entre a cerca das grandes propriedades e as estradas, onde possuem moradia, pequenos cultivos alimentícios e criações de animais, recorrendo ao trabalho por mês ou por dia junto aos proprietários do entorno - até aqueles que combinam diferentes trabalhos por dia e empreitadas, junto de pequenas chácaras. Assim, o simples fato de trabalhar por dia não encerra em si mesmo a condição objetiva na qual um trabalhador está inserido.

Comparando as três trajetórias brevemente apresentadas nesta seção, podemos inferir que, conforme houver maiores margens de autonomia devido à posse de terras suficientes para manejar rebanhos próprios (Adolfo e Roberta), ou então a produção artesanal de bens de consumo sob condições mercadológicas satisfatórias (Cleber e Giovana), o trabalhador/pequeno proprietário tenderá a preferir trabalhar por conta, isto é, 'se governar', não depender dos mandos ou de um compromisso com um estancieiro. Do contrário, temos a condição de Camilo e Angélica, o casal apresentado no início da seção, os quais consideram que a chácara não garante sua autonomia e, assim, o marido se emprega como mensal em estâncias - ou seja, depende do compromisso/subordinação.

Tendo em vista respostas como essas, consideramos que em muitas situações não há uma separação fixa entre ter vínculo laboral com estâncias e ser proprietário de pequena parcela de terra, já que essas condições objetivas são complementares de diversas maneiras. Identificamos que existe separação perceptível entre: a) uma família que se ocupe apenas ou predominantemente em sua propriedade, trabalhando por conta, o que sob certas lentes teóricas poderá ser classificado como 
pecuarista familiar em condição pluriativa (Ribeiro, 2016; Neske, 2016); b) uma família que possui uma chácara ao mesmo tempo em que um de seus membros possui vínculo empregatício como peão de estância, o qual, sob certas lentes teóricas que estudaram o trabalho rural nas regiões marcadas por estâncias no Rio Grande do Sul, poderá ser classificado como trabalhador assalariado (FEE, 1978; Beskow, 1986; Alonso; Benetti; Bandeira, 1994).

Contudo, tratar dessas categorias de forma fixa apresenta limites. Por exemplo: na visão imediata de um peão que não vislumbra, em curto prazo, adquirir terras suficientes para sobreviver apenas delas, alcançar a posição de capataz com uma ponta de gado pode ser um agradável meio termo e, quiçá, um caminho para enfim ter condições de maior autonomia relativa caso puder adquirir maiores parcelas de terra ou iniciar um pequeno negócio na cidade. Mesmo assim, deve-se considerar que as situações sociais são bastante complexas: até mesmo alguém que seja proprietário de certa parcela de terras - como o caso de Adolfo, com 100 hectares junto aos pais - e que possua gado próprio pode optar por um trabalho complementar como diarista, em condição que também considera de maior autonomia perante um mensal. Ou seja, mesmo entre aqueles que trabalham por conta, os graus de subordinação aos grandes proprietários não são ausentes. Fica em aberto realizar novas pesquisas para entender em que medida a estância condiciona a economia local no sentido de constranger a reprodução de um campesinato autônomo em propriedades de diferentes dimensões em seu entorno.

\section{CONSIDERAÇÕES FINAIS}

O presente artigo foi escrito com a finalidade de sistematizar algumas das discussões desenvolvidas no âmbito do grupo de pesquisas 'Economia e sociedade estancieira: trajetórias conexas e práticas de reprodução social' sobre o tema das relações sociais de produção nas estâncias do Rio Grande do Sul, tendo em vista lacunas percebidas na literatura em relação à segunda metade do século XX. As hipóteses construídas ao longo deste trabalho possuem um sentido exploratório, representam questões de estudo que pretendemos dar continuidade em nossas pesquisas.

Quanto à questão geral explicitada nesse artigo, do trabalho nas estâncias, consideramos a existência de estruturas que se mantêm e que se retraem ao longo das últimas décadas. Por mais que as condições de acumulação capitalista dos estancieiros tenham se modificado com as mudanças no mercado de carnes após a década de 1990, as relações com os trabalhadores apresentam uma série de continuidades baseadas na força que reside no estatuto pessoal de dominação. Considera-se que uma assimilação restringida de direitos dos trabalhadores por parte dos empregadores está contida na permanência de sentidos ao trabalho baseados na honra e no compromisso. No entanto, os trabalhadores expressam sinais de que esses princípios estão esgarçados ao reconhecerem vantagens 
em ocupações laborais alternativas e ao acionarem com maior frequência os patrões na justiça do trabalho.

Constata-se que o mundo do trabalho nesse espaço social vai além de uma ideia simplificada da condição de peão. Há um conjunto de trajetórias relativas, complementares e não estanques, nas quais é importante considerar as condições objetivas (terras, terrenos, contratos, atividades, direitos, formas de pagamentos) e subjetivas (prestígio, percepções, sentidos para o trabalho, para autonomia, para o empregador, para as leis) que permeiam cada uma delas, em especial o que os agentes consideram que é necessário fazer em sua posição para seguir vivendo, considerando possibilidades distintas dentro de uma mesma posição geral de peão.

Entendemos que essa complexidade de trajetórias revela insuficiências de um uso simplificado da categoria assalariado (FEE, 1978; Beskow, 1986; Alonso; Benetti; Bandeira, 1994) na análise dos peões de estância do Rio Grande do Sul e das estratégias de reprodução social que estão em jogo nos grupos familiares aos quais estão vinculados. Ao mesmo tempo, entendemos que sua substituição pela noção de pecuarista familiar (Waquil et al., 2016) apresenta outras insuficiências, visto que a vinculação de muitas dessas famílias à dimensão material de trabalho nas grandes propriedades e à dimensão simbólica de suas relações pessoais junto a grandes proprietários tende a ser preponderante nas estratégias postas em jogo. Nesse sentido, não é descartada a validade de ambas as categorias para determinados recortes de relações sociais. Contudo, atenta-se para seus limites e efeitos generalizantes quando alçadas para conjuntos ampliados de agentes sociais, sem levar em conta as teias de interdependência (Elias, 1980) das configurações sociais em que ainda é importante a presença da estância e dos estancieiros.

\section{REFERÊNCIAS}

ALONSO, José Antônio Fialho; BENETTI, Maria Domingues; BANDEIRA, Pedro Silveira. Crescimento econômico da região sul do Rio Grande do Sul: causas e perspectivas. Porto Alegre: FEE, 1994.

BESKOW, Paulo Roberto. O arrendamento capitalista na agricultura: evolução e situação atual da economia do arroz no Rio Grande do Sul. São Paulo: Hucitec; Brasília: CNPq, 1986

BOURDIEU, Pierre. O Poder Simbólico. Rio de Janeiro: Bertrand Brasil, 1989.

BRUMER, Anita. Gênero e agricultura: a situação da mulher na agricultura do Rio Grande do Sul. Revista Estudos Feministas, v. 12, n. 1, p. 205-227, 2004.

BRUMER, Anita. Previdência social rural e gênero. Sociologias, Porto Alegre, v. 4, n. 7, p. 50-81, jan./jun. 2002.

CARDOSO, Fernando Henrique. Capitalismo e escravidão no Brasil meridional: o negro na sociedade escravocrata do Rio Grande do Sul. 5. Ed. Rio de Janeiro: Civilização Brasileira, 2003. 
CARNEIRO, Maria José. Herança e gênero entre agricultores familiares. Revista Estudos Feministas, p. 22-55, 2001.

CERQUEIRA, Ana Carneiro. "Mulher é trem ruim": a "cozinha" e o "sistema" em um povoado nortemineiro. Revista Estudos Feministas, v. 25, n. 2, p. 707-731, 2017.

ELIAS, Norbert. Introdução à sociologia. Braga (Portugal): Editora Pax/Edições 70, 1980.

FARINATTI, Luís Augusto Ebling. Confins Meridionais: famílias de elite e sociedade agrária na fronteira sul do Brasil. Santa Maria: Editora UFSM, 2010.

GARCIA JR., Afrânio Raul. O Sul: caminho do roçado: estratégias de reprodução camponesa e transformação social. São Paulo: Marco Zero; Brasília, DF: Editora Universidade de Brasília: MCTCNPq, 1989.

IBGE - Instituto Brasileiro de Geografia e Estatística. Censo Agropecuário. 2006.

MAESTRI, Mario. O cativo, o gaúcho e o peão: considerações sobre a fazenda pastoril riograndense (1680-1964). In: MAESTRI, Mario (Org.). Peões, gaúchos, vaqueiros, cativos campeiros: estudos sobre a economia pastoril do Brasil. Passo Fundo: Editora Universidade de Passo Fundo, 2010, p. 212-300.

MARTINS, José de Souza. O cativeiro da terra. 9. ed. revista e ampliada. São Paulo: Contexto, 2010. MEDEIROS, Laudelino T. O peão de estância: um tipo de trabalhador rural. Porto Alegre: Instituto de Estudos e Pesquisas Econômicas/UFRGS - Estudos e Trabalhos mimeografados nº 8, 1969.

NESKE, Márcio Zamboni. Mercantilização, heterogeneidade social e autonomia na produção familiar: uma análise da pecuária familiar do Rio Grande do Sul. In: WAQUIL, Paulo Dabdab et al. (Org.) Pecuária familiar no Rio Grande do Sul: história, diversidade social e dinâmicas de desenvolvimento. Porto Alegre: Editora da UFRGS, 2016. p. 131-148.

PALMEIRA, Moacir. Casa e trabalho: nota sobre as relações sociais na plantation tradicional (1977). In: WELCH, C. A.; MALAGODI, E.; CAVALCANTI, J. S. B.; WANDERLEY, M. de N. (Orgs.) Camponeses brasileiros, v. 1. São Paulo: Editora UNESP; Brasília: NEAD, 2009. p. 203-216.

PAULILO, Maria Ignez S. O peso do trabalho leve. Revista Ciência Hoje, v. 5, n. 28, p. 64-70, 1987.

PAULILO, Maria Ignez. Trabalho familiar: uma categoria esquecida de análise. Revista Estudos Feministas, v. 12, n. 1, p. 229-252, 2004.

PICCIN, Marcos Botton. Os senhores da terra e da guerra do Rio Grande do Sul: um estudo sobre as estratégias de reprodução social do patronato rural estancieiro. 2012. $457 \mathrm{f}$. Tese (Doutorado em Ciências Sociais) - Universidade Estadual de Campinas, Campinas. 2012.

PICCIN, Marcos Botton. Patronato estancieiro gaúcho: de subsidiários das lavouras de exportação a produtores de artigos de luxo. Estudos Sociedade e Agricultura, Rio de Janeiro, v. 22, n. 2, p. $327-$ 59, out. 2014.

RIBEIRO, Claudio Marques. O modo de vida dos pecuaristas familiares no pampa brasileiro. In: WAQUIL, Paulo Dabdab et al. (Org.) Pecuária familiar no Rio Grande do Sul: história, diversidade social e dinâmicas de desenvolvimento. Porto Alegre: Editora da UFRGS, 2016. p. 87-108.

RIO GRANDE DO SUL. Secretaria de Coordenação e Planejamento. Fundação de Economia e Estatística. 25 anos de economia gaúcha - a agricultura do Rio Grande do Sul. Porto Alegre, v. 3, 1978.

SEYFERTH, Giralda. Herança e estrutura familiar camponesa. Boletim do Museu Nacional. Rio de Janeiro: Museu Nacional, 1985.

SIGAUD, Lygia. A nação dos homens: uma análise regional de ideologia. Anuário antropológico, v. 3, n. 1, p. 13-114, 1979. 
SIGAUD, Lygia. Direito e coerção moral no mundo dos engenhos. Estudos históricos, v. 9, n. 18, p. 361-388, jul./dez. 1996.

WAQUIL, P. D.; MATTE, A.; NESKE, M. Z.; BORBA, M. (Orgs.) Pecuária familiar no Rio Grande do Sul: história, diversidade e dinâmicas de desenvolvimento. Porto Alegre: Editora da UFRGS, 2016. WEBER, Max. A situação dos trabalhadores rurais na Alemanha nas províncias do Além-Elba. In: SILVA, José Graziano da; STOLCKE, Verena (Orgs.). A Questão Agrária. São Paulo: Brasiliense, 1981, p. 59-80.

WOORTMANN, Klaas. Com parente não se neguceia: o campesinato como ordem moral. Anuário antropológico, v. 87, p. 11-73, 1990.

ZARTH, Paulo Afonso. Do arcaico ao moderno: o Rio Grande do Sul agrário do século XIX. Ijuí: Editora Unijuí, 2002. 